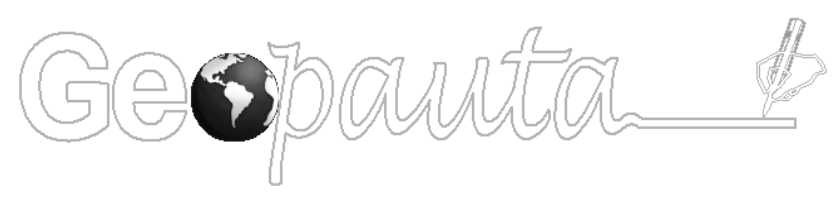

Volume 4, no. 2, 2020

ISSN: 2594-5033

http://periodicos2.uesb.br/index.php/geo

DOI: https://doi.org/10.22481/rg.v4i2.6523

\title{
Vulnerabilidades socioespaciales de la población en ciudades amazónicas del norte de Mato Grosso
}

\section{Vulnerabilidades socioespaciais da população em cidades amazônicas do norte mato- grossense}

\section{Socio-spatial vulnerabilities of the population in amazonian cities in northern Mato Grosso}

Alfredo Zenen Dominguez Gonzalez ${ }^{1}$ http://orcid.org/0000-0002-9192-342X

Emanoel Anésio Andrade Ferreira ${ }^{2}$ http://orcid.org/0000-0001-6587-4196

Vandreia Neves Goulart Melo ${ }^{3}$ http://orcid.org/0000-0002-6452-1409

\footnotetext{
${ }^{1}$ Doutor em Ciências Geográficas, Universidad Havana - Cuba; Professor do Departamento de Geografia e do Programa de Pósgraduação (PPGGEO) da Universidade do Estado de Mato Grosso. alfredodgrv@yahoo.es

${ }^{2}$ Licenciado em Geografia. Professor da rede estadual de ensino no município de Juscimeira - MT-Brasil

${ }^{3}$ Licenciada em Geografia. Professora da rede estadual de ensino no município de Terra Nova do Norte-MT-Brasil
}

\section{Resumen}

Buscando identificar los principales factores condicionantes de vulnerabilidades socioespaciales de la población residente en las cidades mato-grossenses de Terra Nova do Norte, Guarantã do Norte, Peixoto de Azevedo y Matupá, situadas en la cuenca amazónica, fue aplicado un cuestionario semiestruturado en 1150 domicilios. Los resultados apuntan como factores de vulnerabilidad: nivel de escolaridad; presencia de niños y ancianos en los domicilios; características constructivas de los inmuebles; destino de las aguas residuales domésticas y consumo de agua sin tratamiento. Estos últimos contribuyen para la incidencia de diversas enfermedades asociadas al agua y a vectores.

Palabras clave: Peligros climáticos; Sistemas urbanos; Infraestructura.

\section{Resumo}

Esta pesquisa visou identificar os principais fatores condicionantes de vulnerabilidades socioespacias da população residente nas cidades mato-grossenses de Terra Nova do Norte, Guarantã do Norte, Peixoto de Azevedo e Matupá, situadas na bacia amazônica. Para coletar os dados utilizou-se um questionário semiestruturado, aplicado em 1.150 domicílios. Os resultados apontam como principais fatores de vulnerabilidade: nível de escolaridade; presença de crianças e idosos nos domicílios; características construtivas dos imóveis; forma de despejo do esgoto doméstico; e consumo de água sem tratamento. Estes últimos contribuem para a incidência de diversas doenças associadas à água e a vetores.

Palavras chave: Perigos climáticos. Sistemas urbanos. Infraestrutura. 


\begin{abstract}
The research sought to identify the main conditioning factors of socio-spatial vulnerabilities of the population in Terra Nova do Norte, Guarantã do Norte, Peixoto de Azevedo and Matupá, Brazilian cities located in the north of the State of Mato Grosso, in the Amazon basin. For data collection, a semi-structured questionnaire was applied in 1150 households. The results indicate that the main vulnerability factors are: level of education; presence of children and the elderly in households; constructive characteristics of residences; form of sanitary sewage, and consumption of untreated water. Many of these factors contribute to the incidence of waterborne diseases and other diseases associated with vectors.
\end{abstract}

Keywords: Climatic hazards. Urban systems. Infrastructure.

Recibido: 14/04/2020

Aceptado para publicación: 30/06/2020

Publicado em 20/07/2020

\title{
Introducción
}

En las últimas décadas, el aumento del número de desastres naturales ha generado perjuicios diversos, especialmente en países subdesarrollados (MARCELINO, 2008 apud VAZ, 2010). En Brasil se ha registrado una intensificación de los eventos extremos: entre los años 1980 y 2013 ocurrieron 106 desastres relacionados con el clima, colocando al país en la segunda posición entre los países de América Latina y el Caribe, después de México, según CAF (2014).

En las proyecciones regionalizadas de cambios en las precipitaciones $(\mathrm{mm} /$ día $)$ entre el presente y diferentes períodos futuros, “...los centros de máxima reducción de las lluvias se expanden para las regiones de la Amazonia..." (PNA, 2016, p. 18); no obstante, esa reducción del volumen anual puede estar acompañada de un aumento en la ocurrencia de tempestades con lluvias intensas (PNA, 2016) e inundaciones. Tales proyecciones indican que la población enfrentará peligros climáticos, siendo que el nivel de sus impactos dependerá tanto del propio peligro como “....de la exposición [...] y la vulnerabilidad de los sistemas humanos y naturales" (IPCC, 2014, p. 57).

En Brasil, con vulnerabilidad en los ecosistemas naturales, agroecosistemas y sistemas socioeconómicos (OLIVEIRA e NOBRE, 2008), una reducida capacidad adaptativa dentro de los países de América Latina y el Caribe (CAF, 2014) y un elevado índice de urbanización “...los estreses climáticos podrán resultar en efectos cascada [en los] diferentes sistemas 
urbanos de infraestructura, que son interdependientes entre sí, como los sectores de agua, saneamiento, energia y transporte...” (PBMC, 2016, p. 4).

Las ciudades brasileñas son vulnerables al cambio climático debido a factores como: eliminación de ecosistemas asociada al rápido crecimiento urbano; insuficiencia de servicios básicos de saneamiento, y riesgo de desabastecimiento de agua y energia por causa del deterioro cuantitativo y cualitativo de los recursos hídricos (PBMC, 2016).

Buscando conocer las particularidades de las vulnerabilidades frente al cambio climático en las ciudades situadas al norte del estado de Mato Grosso, fué implementado un proyecto de investigación sobre el tema, del cual se deriva este artículo, que responde al objetivo de identificar los factores condicionantes de vulnerabilidades socioespaciales de la población residente en ciudades de la Región de Planeamiento II-Norte de Mato Grosso.

El área estudiada corresponde al perímetro urbano de las ciudades de Terra Nova do Norte, Guarantã do Norte, Matupá y Peixoto de Azevedo, sedes de los municipios de igual nombre, localizados en el extremo norte del estado de Mato Grosso (mapa 1), formando parte de la Región de Planeamiento II - Norte (Alta Floresta) (MATO GROSSO, 2017).

Mapa 1- Localización de las ciudades estudiadas en el contexto regional
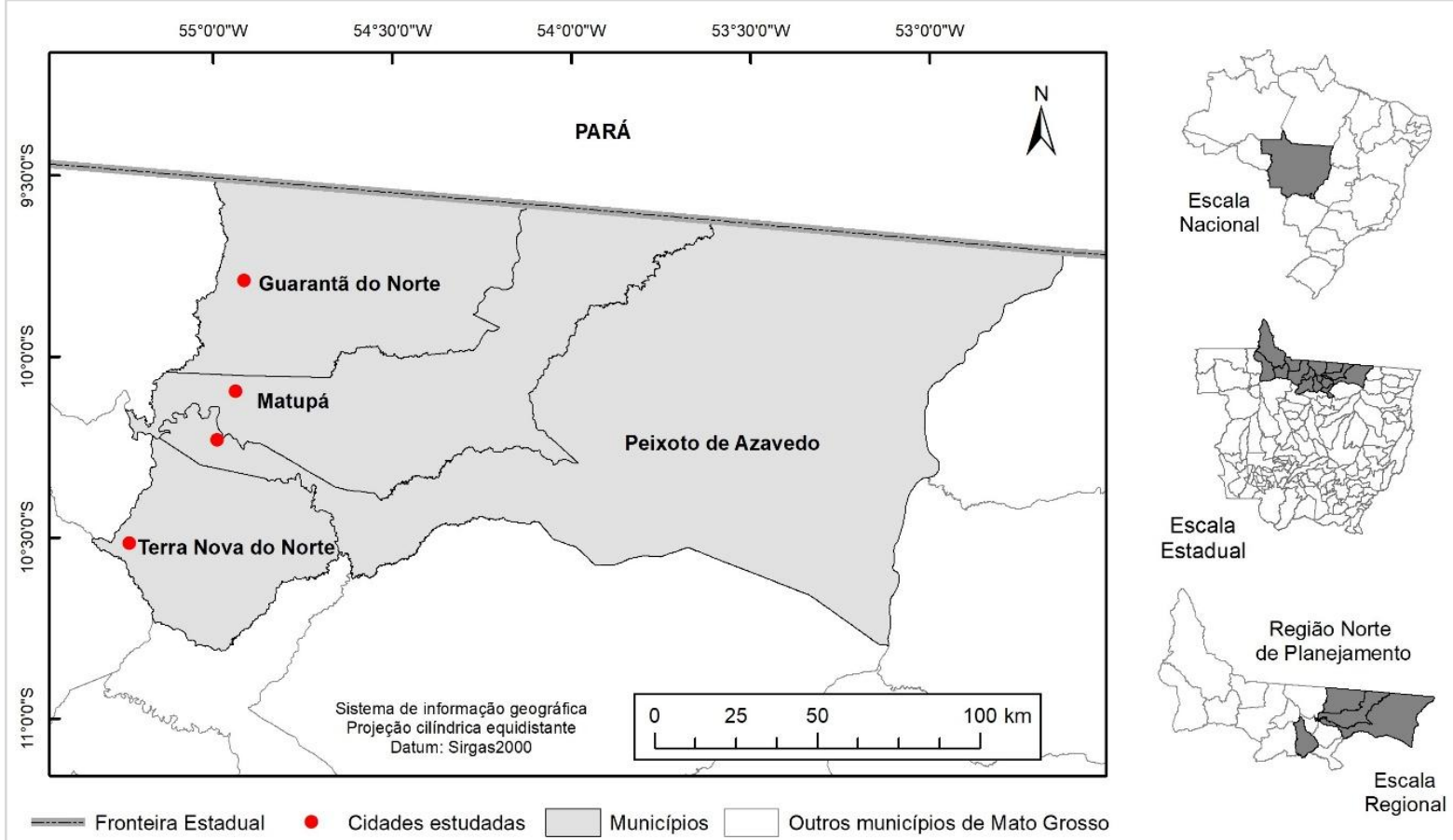

Fuente: Autores, ( 2019).

De acuerdo con autores como Moreno (2005) y Ferreira y Silva (2008), el origen de esas ciudades está asociado al proceso de ocupación de la Amazonia estimulado por el Programa de Integración Nacional (PIN) del gobierno federal, que propició la apertura de la 
carretera BR 163 (Cuiabá-Santarém) y la implementación de proyectos de colonización del Instituto Nacional de Colonización y Reforma Agraria-INCRA y empresas particulares (Colonizadora Líder S.A., Agropecuaria Cachimbo, Cooperativa Agropecuaria Mixta de Canarana-COOPERCANA y Cooperativa Tritícola de Erechim Ltda-COTREL), desde los años 1970.

Esas empresas deberían demarcar las tierras y construir la infraestructura básica necesaria para las familias que fuesen dislocadas para la región (PANNUTI, 2002). Esto último no ocurrió completamente, pues realmente los proyectos estimularon la explotación forestal y mineral y la expansión de la producción agropecuaria, provocando profundas modificaciones de las condiciones ambientales originales (OLIVEIRA, 2007). En ese contexto surgieron los actuales municipios de Terra Nova do Norte, Guarantã do Norte, Matupá y Peixoto de Azevedo, todos desmembrados en 1986, del municipio de Colíder, que había sido creado por la Ley Estadual no. 4.158/1979. Apenas Matupá fue emancipado en 1988.

\section{Procedimientos metodológicos}

Las ciudades de Terra Nova do Norte, Guarantã do Norte, Matupá y Peixoto de Azevedo fueron seleccionadas para el estudio por ser las capitales de municipios que representan las principales actividades económicas de la región: agricultura, pecuária, explotación forestal y mineración. El universo de la investigación estuvo compuesto por los responsables de domicilios en barrios seleccionados de esas ciudades.

Los criterios de selección de la muestra fueron los siguientes: (1) que estuvieran representados al menos $10 \%$ de los barrios de cada ciudad estudiada; (2) que la persona muestreada fuese uno de los responsables del domicilio; (3) que esa persona tuviese una edad entre 21 y 80 años. Por tanto, la muestra fue escogida intencionalmente, por incluir los responsables de domicilios a ser muestreados y considerar su edad.

Paralelamente, los barrios fueron seleccionados aleatoriamente en cada ciudad, siendo: 2 en Terra Nova do Norte, 4 en Guarantã do Norte, 4 en Matupá y 3 en Peixoto de Azevedo. La Tabla 1 muestra algunos datos demográficos y el número de domicilios muestreados en esas ciudades.

El levantamiento de datos para evaluar la percepción de los responsables de domicilios en relación con sus vulnerabilidades se hizo utilizando un cuestionario semiestructurado (el cual pasó por las fases de test, revisión y validación). Ese cuestionario fue elaborado con base 
en autores como Whyte (1977, apud ABREU y ZANELLA, 2015); Menezes; Oliveira; El-Dir (2011); Lindoso; Eiró; Rocha (2013) y Marandola Júnior y Modesto (2012).

Tabla 1- Población urbana y domicilios muestreados en las ciudades estudiadas.

\begin{tabular}{c|c|c|c|c}
\hline Ciudad & $\begin{array}{c}\text { Población total del } \\
\text { municipio }\end{array}$ & $\begin{array}{c}\text { Población } \\
\text { urbana }\end{array}$ & $\begin{array}{c}\text { Total de } \\
\text { domicilios }\end{array}$ & $\begin{array}{c}\text { Domicilios } \\
\text { muestreados }\end{array}$ \\
\hline Terra Nova do Norte & 11.291 & 4.500 & 3.568 & 230 \\
\hline Guarantã do Norte & 32.216 & 23.940 & 9.397 & 380 \\
\hline Matupá & 14.174 & 10.927 & 4.276 & 240 \\
\hline Peixoto de Azevedo & 30.812 & 19.804 & 8.707 & 300 \\
\hline
\end{tabular}

Fuente: IBGE (2015, apud MATO GROSSO, 2017).

El cuestionario fue organizado en bloques, cuyas cuestiones buscaban conocer aspectos relacionados com: el perfil sociodemográfico de las personas (número de residentes en el domicilio, nivel de escolaridad del entrevistado, número y edad de los niños residentes en el domicilio, presencia de personas ancianas y/o discapacitadas, tiempo de residencia y motivos para vivir en el barrio); la vulnerabilidad de las casas (asociada al uso y características constructivas del inmueble y a los servicios de saneamiento básico) y las afectaciones provocadas por eventos meteorológicos en el domicilio y en la salud de las personas.

Fueron muestreados 1150 domicilios en los barrios seleccionados de las diferentes ciudades, siendo realizado a seguir, el análisis e interpretación de los datos colectados durante la aplicación del cuestionario, utilizando la estadística descriptiva. Finalmente se discutieron los resultados, relacionándolos con los obtenidos en otras investigaciones sobre el tema.

\section{Saneamiento básico e infraestructura nos municipios do norte mato-grossense}

Los municipios de la Região de Planejamento II - Norte (Alta Floresta) presentan problemas de saneamiento e infraestructura básica, como indica el documento "Regiões de Planejamento do Estado de Mato Grosso" (MATO GROSSO, 2017). En el caso de los municipios de Terra Nova do Norte, Guarantã do Norte, Matupá y Peixoto de Azevedo, todos presentan necesidades significativas en relación con los servicios básicos en general (Tabla 2).

Tabla 2- Condiciones del saneamiento y la infraestructura en los municipios

\begin{tabular}{c|c|c|c|c}
\hline \multirow{2}{*}{ Municipio } & \multicolumn{2}{|c|}{ Domicilios con servicios básicos (\%) } & $\begin{array}{c}\text { Drenaje para fosa séptica } \\
\text { en los domicilios con } \\
\text { baño sanitario (\%) }\end{array}$ \\
\cline { 2 - 4 } & $\begin{array}{c}\text { Colecta } \\
\text { de RSU }\end{array}$ & $\begin{array}{c}\text { Drenaje } \\
\text { sanitario }\end{array}$ & $\begin{array}{c}\text { Agua canalizada } \\
\text { (red) }\end{array}$ & 12,07 \\
\hline Terra Nova do Norte & 48,85 & 12,5 & 45,52 & 2,14 \\
\hline Guarantã do Norte & 75,72 & 2,5 & 64,35 & 9,93 \\
\hline Matupá & 70,18 & 10,2 & 65,12 & 0,28 \\
\hline Peixoto de Azevedo & 64,67 & 6,2 & 52,36 & \\
\hline
\end{tabular}

Fuente: Elaborado por los autores con base en Mato Grosso (2017). 
La Tabla 2 evidencia una insuficiente cobertura de recolección de resíduos sólidos urbanos (RSU), distribución de agua potable y drenaje sanitario (esta última extremadamente reducida). Véase que, en los domicilios que poseen baño, casi todo el drenaje se realiza para "otro desagüe" por la limitada disponibilidad de fosas sépticas. Paralelamente, la red de distribución de agua potable no beneficia a toda la población, obligando a muchas familias a captar agua de pozos o manantiales (MATO GROSSO, 2017). Em muchos barrios esos problemas de planificación propician la incidencia de enfermedades y problemas sociales, como apuntaran Souza et al. (2008) en estudio de la ciudad de Peixoto de Azevedo.

Al mismo tempo, la insuficiente infraestructura de drenaje pluvial favorece la ocurrencia de "enxurradas" (grande volumen de agua fluyendo por las calles) e inundaciones: según CEPED (2013) entre los años 1991 y 2012 ocurrieron enxurradas en Matupá (2000 y 2006); Peixoto de Azevedo (1995 y 2005) y Terra Nova do Norte (2005 y 2006), así como inundaciones en Guarantã do Norte (2000) y Matupá (1998, 2001, 2003, 2005 y 2007).

\section{Vulnerabilidades socioespaciales de la población en las ciudades estudiadas}

El perfil de las personas muestreadas indica un predominio de las mujeres $(55,9 \%$ de la muestra) sobre los hombres $(44,1 \%)$. En relación a la distribución por fajas etarias, en todas las ciudades predominan las personas con edades entre 31 y 60 años (Tabla 3), lo que permite inferir que se trata de sujetos maduros.

Tabla 3- Distribución de la muestra por sexo y edad

\begin{tabular}{c|c|c|c|c|c|c|c|c}
\hline \multirow{2}{*}{ Ciudad } & \multicolumn{2}{|c|}{$\begin{array}{c}\text { Distribución } \\
\text { por sexos (\%) }\end{array}$} & \multicolumn{6}{c}{ Distribución por fajas etarias, en años (en \% de las } \\
& Mersonas muestreadas) \\
\cline { 2 - 9 } & Masc. & Fem. & $\mathbf{2 1 - 3 0}$ & $\mathbf{3 1 - 4 0}$ & $\mathbf{4 1 - 5 0}$ & $\mathbf{5 1 - 6 0}$ & $\mathbf{6 1 - 7 0}$ & $\mathbf{7 1 - 8 0}$ \\
\hline Terra Nova do Norte & 43,91 & 56,09 & 6,09 & 13,04 & 34,78 & 26,09 & 16,08 & 3,91 \\
\hline Guarantã do Norte & 40,37 & 59,62 & 15,64 & 28,91 & 26,79 & 18,30 & 8,22 & 2,13 \\
\hline Matupá & 43,75 & 56,25 & 8,75 & 27,91 & 17,5 & 26,25 & 12,08 & 7,5 \\
\hline Peixoto de Azevedo & 49,00 & 51,00 & 23,00 & 29,00 & 15,00 & 13,00 & 13,33 & 6,66 \\
\hline
\end{tabular}

Fuente: Elaborado por los autores basado en el trabajo de campo (2019).

Con relación al nivel de escolaridad del responsable por la residencia, la mayoría declaró no haber terminado la Enseñanza Fundamental ( $1^{0}$ a $9^{0}$ grados $)$, o la Enseñanza Media (Gráfico 1); además, muy pocas personas concluyeron la Enseñanza Superior y alrededor de $5,0 \%$ de ellas están cursando ese nivel. Aún cuando existen instituciones privadas que ofertan cursos en la modalidad de Educación a Distancia en las ciudades estudiadas, las dificultades financieras de las personas podrían estar limitando el acceso a los mismos. 
Gráfico 1- Nivel de escolaridad de las personas muestreadas

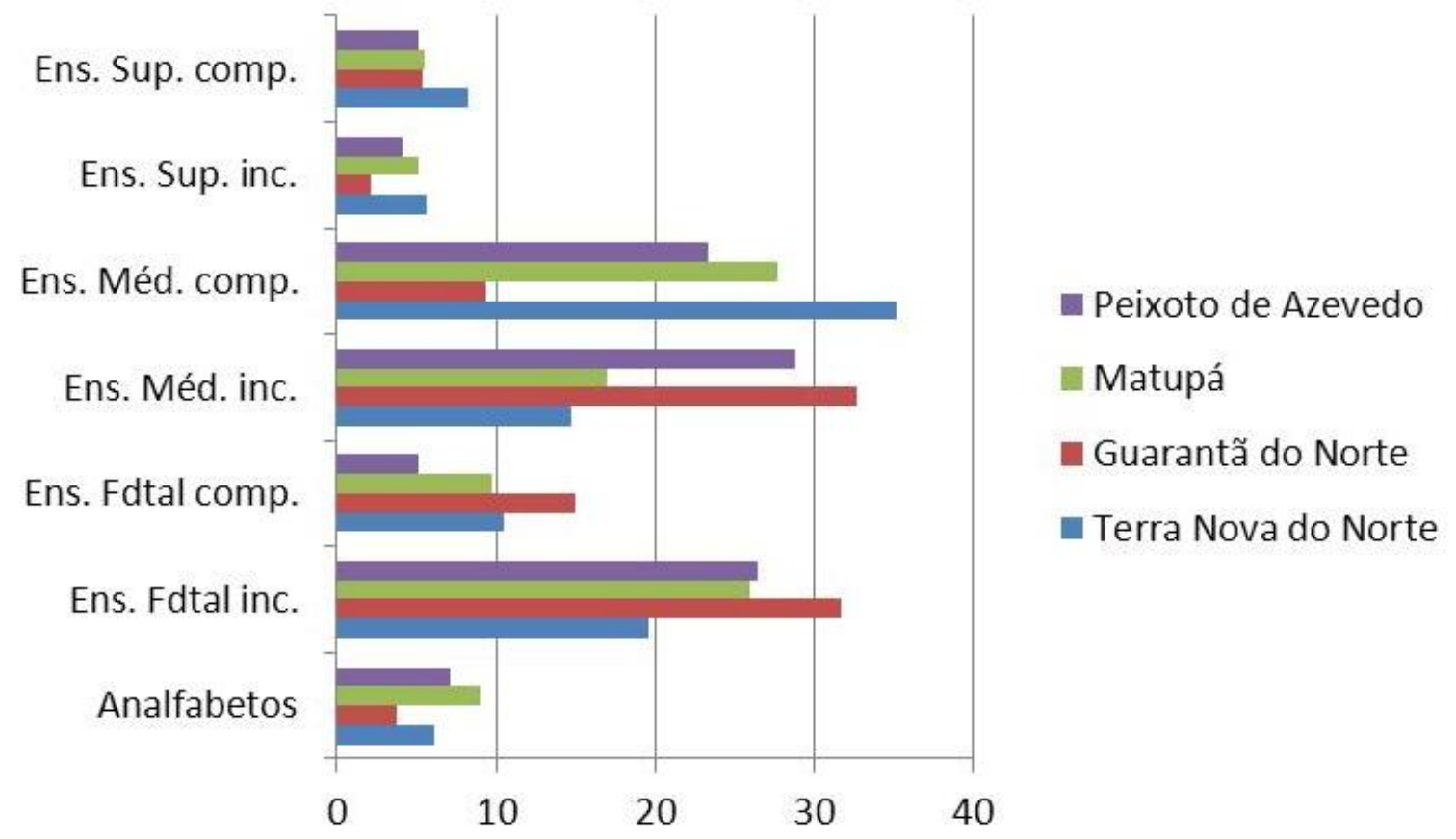

Fuente: Elaborado por los autores basado en el trabajo de campo (2019).

También existen ofertas de enseñanza superior pública en los campus de Alta Floresta y Colíder, pertenecientes a la Universidad Estadual de Mato Grosso (UNEMAT); no obstante, la distancia hasta ellos constituye un factor limitante para los habitantes de las ciudades estudiadas (apenas los alumnos de Peixoto de Azevedo y Terra Nova do Norte tienen transporte garantizado diariamente para llegar al campus de Colíder). Paralelamente, nuevas oportunidades de educación a distancia en instituciones públicas están surgiendo con la creación de Núcleos Pedagógicos (en Matupá) y de Polos de Apoyo Presencial de la Universidad Abierta de Brasil (UAB) como el de Guarantã do Norte.

Cuando analizada la proporción de personas con nivel medio completo y superior, el Gráfico 1 muestra una diferencia notable, lo que difiere de lo encontrado en estudios como los de Bursztyn y Eiró (2015) y Souza y Castro (2017) algo que podría estar asociado a las dificultades de acceso antes citadas. .

Considerando la influencia en la vulnerabilidad de factores como: número de residentes en el domicilio, presencia de personas en edades extremas (niños y ancianos) y discapacitados, las personas fueron cuestionadas sobre estos aspectos. En relación al número de residentes, las respuestas muestran que en la mayor parte de los domicilios de todos los barrios estudiados, viven entre 3 y 4 personas (Gráfico 2). El mayor contraste se registra entre las ciudades de Terra Nova do Norte (con un relativo equilibrio entre domicilios con uno a dos y tres a cuatro habitantes) y Peixoto de Azevedo (con un porciento elevado de domicilios donde residen entre 5 y 6 personas, o aún más de 6 ). 
Gráfico 2- Cantidad de personas residentes en los domicilios muestreados

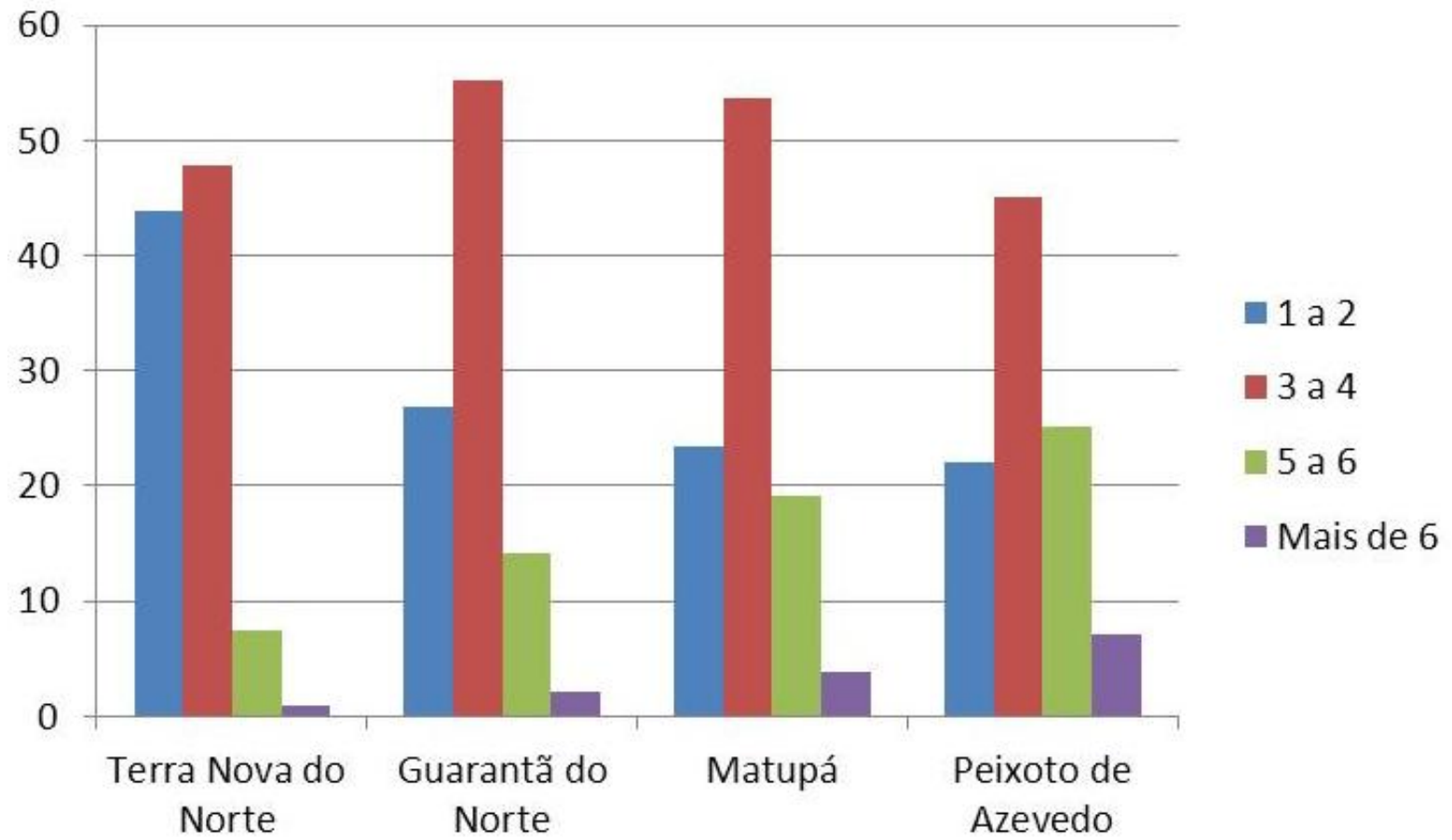

Fuente: Elaborado por los autores basado en el trabajo de campo (2019).

En cuanto al número de niños residentes en los domicilios, apenas en Guarantã do Norte existe un relativo equilibrio entre aquellos con 1 a 2 y 3 a 4 niños (Tabla 4).

Tabla 4- Niños en los domicilios muestreados y su edad (en \% del total muestreado)

\begin{tabular}{l|c|c|c|c|c|c}
\hline \multirow{2}{*}{ Ciudad } & Presencia & \multicolumn{3}{c|}{ Número de niños } & \multicolumn{2}{c}{ Fajas etarias (años) } \\
\cline { 3 - 7 } & de niños & 1 a 2 & 3 a 4 & Más de 4 & 0 a 9 & 10 a 14 \\
\hline Terra Nova do Norte & 48,7 & 74,1 & 20,53 & 5,37 & 66,96 & 33,04 \\
\hline Guarantã do Norte & 42,63 & 46,30 & 51,85 & 1,85 & 65,43 & 34,56 \\
\hline Matupá & 61,66 & 72,29 & 25,67 & 2,03 & 74,32 & 25,68 \\
\hline Peixoto de Azevedo & 69,0 & 57,48 & 29,46 & 13,05 & 71,01 & 28,98 \\
\hline
\end{tabular}

Fuente: Elaborado por los autores basado en el trabajo de campo (2019).

En las restantes ciudades predominan los domicilios con 1 a 2 niños; no obstante, cuando analizada la edad de los mismos se nota el predominio de la faja etária 0 - 9 años, lo que constituye un factor de vulnerabilidad frente a posibles desastres asociados a eventos hidrometeorológicos extremos.

La presencia de ancianos en los domicilios es significativa en Matupá (43,3\% del total muestreado) y Terra Nova do Norte $(37,8 \%)$. En las restantes ciudades la proporción es menor: $18,4 \%$ en Guarantã do Norte y $20,3 \%$ en Peixoto de Azevedo. En estas ciudades los ancianos pueden disfrutar de un estilo de vida más saludable que los que viven en grandes centros urbanos, como afirman Almeida et al. (2016) en estudio realizado en Minas Gerais. No obstante, la pérdida gradual de sus capacidades funcionales incrementa su vulnerabilidad (aún más en ciudades con problemas de infraestructura y servicios, como afirman Bodstein; 
Lima; Barros, 2014). Vale destacar que los niños y ancianos configuran una vulnerabilidad intrínseca, por estar en fajas etarias extremas (ROGERS y BALLANTYNE, 2008).

En relación a los discapacitados, aunque su presencia es menos significativa, ellos pueden constituir un importante factor de vulnerabilidad de las familias en situaciones de emergencia por eventos extremos: en Peixoto de Azevedo, 10,0\% dos domicilios muestreados tienen personas discapacitadas, siendo menor la proporción en las otras ciudades: 8,16\% en Guarantã do Norte, 6,96\% en Terra Nova do Norte e 5,0\% en Matupá.

Gráfico 3 - Tiempo de residencia de las personas muestreadas en el actual municipio.

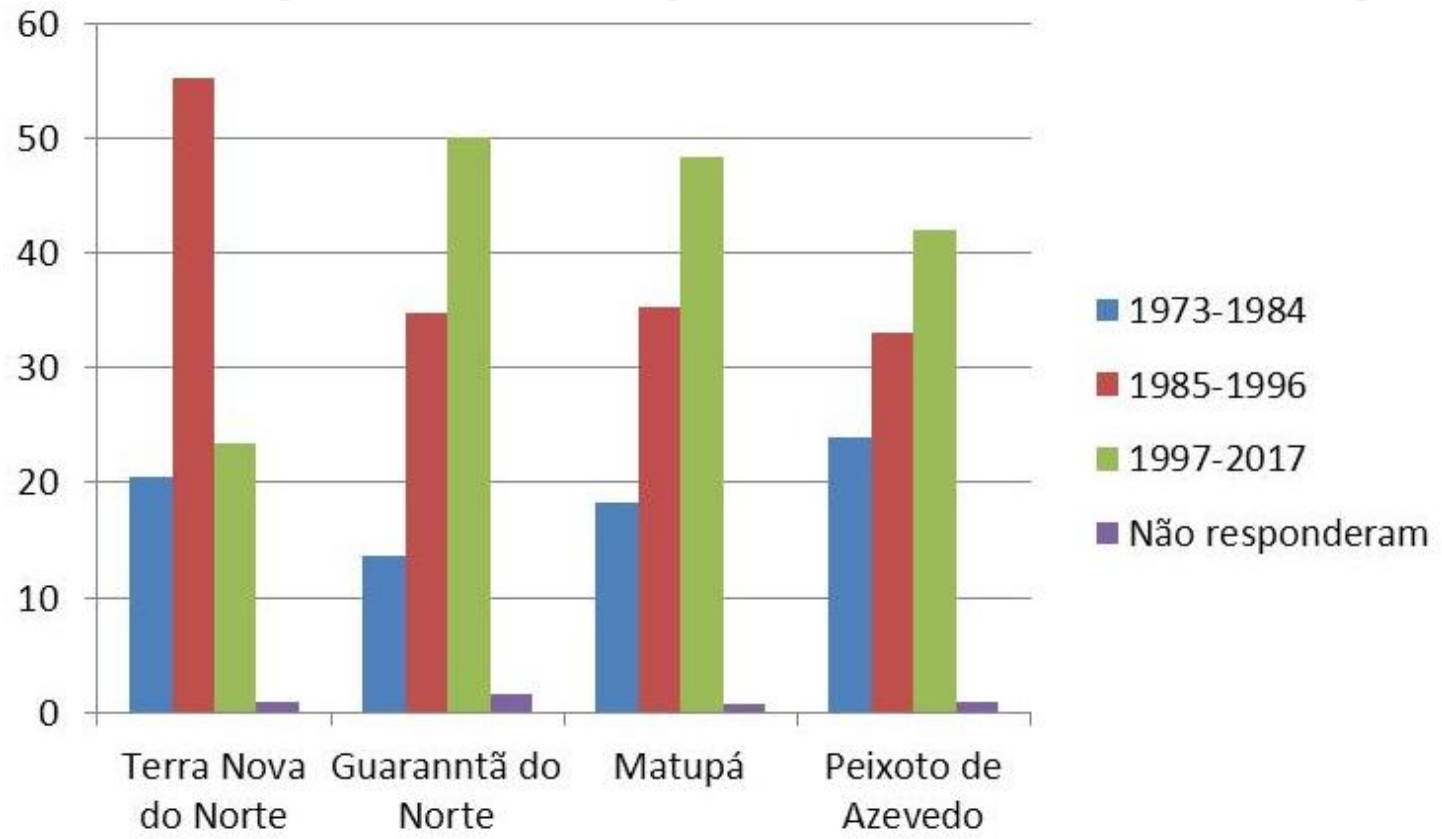

Fuente: Elaborado por los autores basado en el trabajo de campo (2019).

Sobre la formación de una identidad con el lugar, autores como Mourão y Cavalcante (2006) y Novack (2015) destacan el papel de las relaciones sociales y las experiencias de vida (memoria colectiva en una ciudad o barrio, por ejemplo) en el surgimiento del sentido de pertenencia al lugar. Esto llevó a preguntar sobre este aspecto, considerando tres etapas del proceso de ocupación de la región norte de Mato Grosso, definidas para esta investigación: 1973-1984 (cuando aún los actuales municipios formaban parte de Colíder); 1985-1996 (etapa de creación y consolidación de los nuevos municipios); y 1997-2017.

Los resultados evidencian que la mayor parte de las personas investigadas llegó en la época de creación y consolidación de los actuales municipios (1985-1996) o posteriormente (1997-2017), reflejando un rápido proceso de crecimiento poblacional relacionado, principalmente, con la migración desde otras regiones de Brasil (Gráfico 3).

El tiempo de residencia en el actual domicilio es de más de 10 años en la mayoría de las personas muestreadas: 62,6\% en Terra Nova do Norte, 65,3\% en Guarantã do Norte, 62,5\% 
en Matupá e 66,0\% en Peixoto de Azevedo. Esos datos garantizan confiabilidad con relación a las respuestas obtenidas sobre otros factores de vulnerabilidad como: motivos para vivir en el lugar, servicios urbanos, afectaciones del inmueble por eventos meteorológicos, e incidencia de enfermedades en los domicilios.

Cuando analizadas las respuestas sobre los motivos que llevan a las personas a vivir en el barrio (Gráfico 4) el acceso a los servicios ofrecidos en los Puestos de Salud resultó significativo en todas las ciudades (excepto en Peixoto de Azevedo) siendo un resultado similar al obtenido por Marandola Júnior e Modesto (2012) en investigación realizada en Regiones Metropolitanas del Estado de São Paulo: Campinas y Baixada Santista.

Gráfico 4- Motivos para vivir en el barrio (en \% de las respuestas obtenidas)

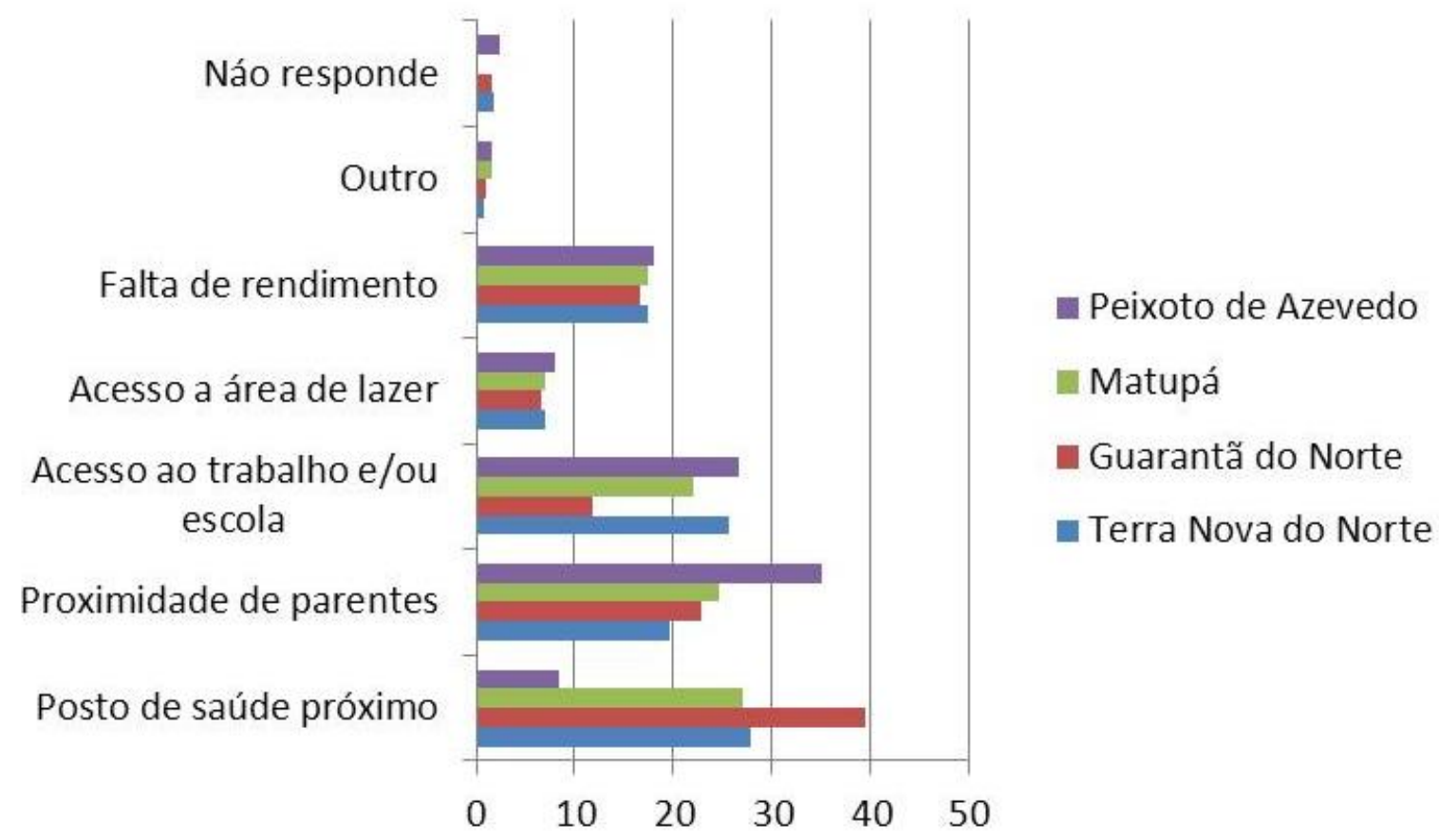

Fuente: Elaborado por los autores basado en el trabajo de campo (2019).

En las restantes ciudades la proximidad de parientes recibió también una elevada frecuencia de respuestas (con mayor destaque para Peixoto de Azevedo), lo que puede estar relacionado con el fuerte flujo migratorio para la región, en el cual el parentesco tiene influencia, como constatado en conversaciones informales con muchos habitantes de las ciudades estudiadas. Otro motivo señalado fue la proximidad al trabajo y/o escuela, aspecto importante para ciudades donde, ante la ausencia de algún sistema de transporte público, las personas deben dislocarse en medios alternativos (especialmente motos y bicicletas) para atender todas sus necesidades.

Muchos de los motivos apuntados (proximidad de Puestos de Salud, del trabajo y/o escuela y de áreas de recreación) indican que existe una percepción sobre el papel del poder 
público en la gestión del espacio urbano, en todas las ciudades estudiadas. Finalmente, el Gráfico 4 muestra, también, la importancia que tiene para las personas el factor "falta de rendimiento" como barrera para que ellas busquen un lugar más apropiado para vivir.

En relación a los usos de los inmuebles por los propietarios, se confirmó que la gran mayoría de ellos lo utiliza apenas como vivienda, siendo que el uso comercial es muy poco expresivo (inferior a 4,0\% del total en todas las ciudades) y el uso mixto es significativo apenas en Matupá, donde 15,0\% de los inmuebles investigados se utiliza como residencia y comercio, simultáneamente. Esta realidad de Matupá puede estar relacionada a la previsión en el Plan Director de la ciudad, de zonas habitacionales organizadas en barrios con comercio y servicios propios, aspecto revelado por Souza et al. (2007).

La calidad de las construcciones residenciales ejerce influencia en la vulnerabilidad, como afirmado por Welz e Krellenberg (2016), y esa calidad interfiere en el confort térmico, dependiente de las propiedades térmicas de los materiales usados en la construcción (DUARTE, 2016). Con base en esta realidad fue formulada a cuestión siguiente: cuales materiales fueron utilizados en la construcción del inmueble que el(la) señor(a) ocupa?. Las respuestas ofrecidas aparecen en el Gráfico 5, donde se nota que la mayoría de los inmuebles fue construida con paredes de mampostería: $75,2 \%$ en Terra Nova do Norte, $62,4 \%$ en Guarantã do Norte, 70,4\% en Matupá y 65,0\% en Peixoto de Azevedo.

Gráfico 5- Características constructivas de los inmuebles muestreados

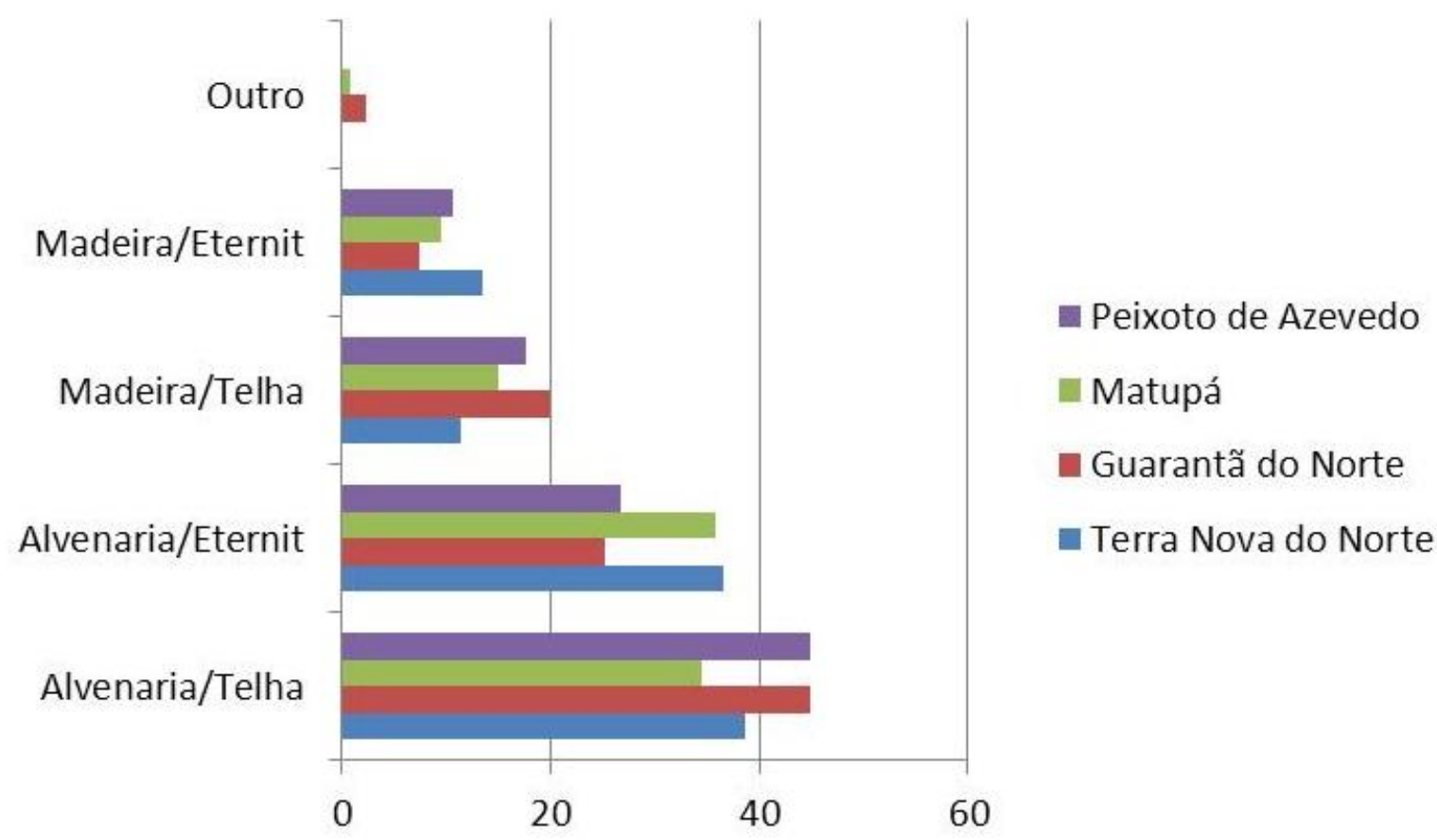

Fuente: Elaborado por los autores basado en el trabajo de campo (2019). 
Una de las funciones de las paredes es impedir el paso de calor para el ambiente interno del inmueble, siendo que en las de mampostería (opacas) la intensidad del flujo de calor que las atraviesa depende, entre otros factores, del coeficiente de absorción de la radiación solar, que es de 0,65 a 0,80 para el ladrillo de color rojo, según Frota e Schiffer (2001). Por tanto, el revestimiento de esas paredes es fundamental para garantizar confort térmico.

Cuando analizado el tipo de material usado en los techos se percibe que 39,2\% del total de viviendas muestreadas poseen techo de Eternit (teja de amianto o fibrocemento) cuya elevada capacidad de absorción de la radiación solar y conductividad térmica (de 0,95 según la NBR 15220/2003) hacen que produzca un fuerte flujo térmico que se transmite para el interior de la vivienda durante el periodo diurno, comprometiendo el confort (SEVEGNANI; GHELFI FILHO; SILVA, 1994; ABREU et. al., 2011), especialmente cuando la familia no posee recursos para colocar algún material aislante bajo el techo, ni para pintar las tejas con pintura acrílica buscando reducir el calor en el interior de la casa.

Contrariamente, en la teja de barro esos procesos de calentamiento diurno y enfriamiento nocturno son más lentos debido a la mayor capacidad térmica de este material (SANTOS e PIMENTEL, 2012) lo que hace que ellas ofrezcan mayor confort térmico, algo reconocido por autores como Sevegnani; Ghelfi Filho; Silva (1994) e Kawabata (2003).

Otra cuestión estaba relacionada con el revestimiento de los inmuebles construidos de mampostería. En las respuestas obtenidas se percibe que en las diferentes ciudades, entre 41 y $58 \%$ de esas paredes están revestidas, parcial o totalmente (Tabla 5).

Tabla 5- Características del revestimiento de los inmuebles muestreados

\begin{tabular}{l|c|c|c|c|c|c}
\hline \multirow{2}{*}{ Ciudad } & \multicolumn{2}{|c|}{$\begin{array}{c}\text { Inmuebles } \\
\text { revestidos }\end{array}$} & $\begin{array}{c}\text { Cobertura del } \\
\text { revestimiento }\end{array}$ & \multicolumn{2}{c}{$\begin{array}{c}\text { Características del } \\
\text { revestimiento }\end{array}$} \\
\cline { 2 - 7 } & Quant. & $\%$ do total & Total & Parcial & Repello & Repello y pintura \\
\hline Terra Nova do Norte & 113 & 49,13 & 26,59 & 38,73 & 70,79 & 29,21 \\
\hline Guarantã do Norte & 157 & 41,32 & 33,33 & 32,91 & 59,35 & 40,64 \\
\hline Matupá & 121 & 50,42 & 31,36 & 40,24 & 55,62 & 44,38 \\
\hline Peixoto de Azevedo & 174 & 58,0 & 50,77 & 38,46 & 68,2 & 31,8 \\
\hline
\end{tabular}

Fuente: Elaborado por los autores basado en el trabajo de campo (2019).

No obstante, es notable el número de inmuebles donde ese revestimiento es parcial, una situación presente en todas las ciudades estudiadas. Destacamos que en las observaciones realizadas en los barrios fue verificado que las personas priorizan la pared frontal en el revestimiento exterior de la vivienda (la cual también recibe pintura en algunos casos).

Sobre este punto, vale destacar que el repello de colores claros (con Coeficiente de Absorción de la Radiación Solar-CARS de 0,3-0,5, según DUARTE, 2016) ayuda a reducir el calentamiento de esas viviendas. Sin embargo, las condiciones económicas de los residentes 
puede estar limitando el uso de algún material aislante debajo de la capa de repello (método más usado actualmente, de acuerdo con FIEGENBAUM, 2018). De cualquier forma, en las paredes de ladrillo (con o sin repello) los procesos de calentamiento y enfriamiento son más rápidos en la parte exterior que en la interior, algo constatado por Fiegenbaum (2018).

La Tabla 5 también muestra que existen pocas viviendas que han sido pintadas, siendo que la aplicación de pintura podría mejorar su desempeño térmico si fuese blanca (porque su CARS es de 0,2-0,3) o comprometerlo (si fuese carmelita oscuro o negro, por ejemplo, cuyo coeficiente oscila entre 0,9 y 1,0 según CROISET, 1972, apud FROTA e SCHIFFER, 2001).

Las observaciones de campo realizadas como parte de esta investigación confirmaron que, en general, los barrios estudiados en todas las ciudades tienen muchas casas de bajo nivel, con paredes de ladrillo o madera y techo de tejas de barro o amianto, siendo casas pequeñas con poca ventilación y a veces aglomeradas; además, poseen muros separando una de otra, cuya emisión de calor contribuye para un calentamiento más intenso de las viviendas.

El hecho de que la cobertura de la red de drenaje sanitario en los barrios estudiados sea muy reducida, obliga a los residentes a realizar el desagüe en fosas (sépticas o rudimentarias), en $100,0 \%$ de las viviendas muestreadas en Terra Nova do Norte, 91,8\% en Guarantã do Norte, 80,4\% en Matupá y 91,3\% en Peixoto de Azevedo.

El acceso a los servicios públicos de abastecimiento de agua potable y colecta de residuos sólidos urbanos es presentado en la Tabla 6, donde se aprecia que, en el caso del abastecimiento de agua a través de la red de distribución, apenas en Matupá este servicio cubre la totalidad de las viviendas muestreadas.

Tabla 6- Alcance del abastecimiento de agua potable y la colecta de RSU (en \% del total)

\begin{tabular}{c|c|c|c|c|c|c}
\hline \multirow{2}{*}{ Ciudad } & \multicolumn{3}{|c|}{ Abastecimiento de agua } & \multicolumn{2}{c}{ Disposición de los residuos sólidos } \\
\cline { 2 - 7 } & Red & Pozo & Carro-pipa & Colectado & Quemado & Enterrado \\
\hline Terra Nova do Norte & 88,26 & 11,74 & 0,0 & 93,47 & 5,22 & 1,30 \\
\hline Guarantã do Norte & 89,47 & 10,52 & 0,0 & 92,10 & 5,79 & 2,1 \\
\hline Matupá & 100,0 & 0,0 & 0,0 & 93,33 & 5,42 & 0,0 \\
\hline Peixoto de Azevedo & 91,0 & 6,0 & 3,0 & 96,0 & 2,0 & 2,0 \\
\hline
\end{tabular}

Fuente: Elaborado por los autores basado en el trabajo de campo (2019).

En las restantes ciudades una parte de las familias respondió que utilizan pozos como fuente de obtención de agua, lo que lleva al riesgo de contraer enfermedades de origen hídrico. También el uso de carros-pipa por 3,0\% de las familias investigadas en Peixoto de Azevedo puede generar riesgos debido al consumo de agua sin el debido tratamiento.

La colecta de residuos sólidos urbanos es realizada regularmente por el poder público en la gran mayoría de las viviendas muestreadas. No obstante, aún existen casos donde esos 
residuos son quemados o enterrados, contribuyendo para la contaminación del agua subterránea.

Los problemas de infraestructura indican que existe vulnerabilidad social derivada de la distribución desigual de los recursos (vulnerabilidad extrínseca o contextual, según ROGERS e BALLANTYNE, 2008), que puede tornar a las personas susceptibles a los impactos causados por un evento meteorológico. Estos factores fueron destacados por autores como Veyret (2007), Martis y Ferreira (2012), Chang (2013), Cavalcante y Aloufa (2014) y Welz y Krellenberg (2016) y por el informe del IPCC (2014). En las ciudades de América Latina, esos factores limitan el acceso a los recursos, obligando a las personas a vivir en zonas vulnerables y/o en casas construidas con materiales precarios (TORRES, 2000; HARDOY y PANDIELLA, 2009).

Buscando conocer mejor las vulnerabilidades de las familias investigadas, fue preguntado si la vivienda ha sufrido afectaciones por causa de eventos como tempestades y lluvias intensas y/o prolongadas. Las respuestas permitieron verificar que los fuertes vientos asociados a tempestades locales han provocado averías en los inmuebles (daños en vidrios de ventanas y puertas, así como en los techos) en 43,7\% de los casos estudiados en Guarantã do Norte, 22,0\% en Peixoto de Azevedo, 14,3\% en Matupá y 11,2\% en Terra Nova do Norte.

En el caso de las inundaciones, estas han ocurrido en todas las ciudades estudiadas durante lluvias intensas y/o prolongadas (afectando 27,6\% de las viviendas muestreadas en Guarantã do Norte, 22,0\% en Peixoto de Azevedo, 15,4\% en Matupá y 6,9\% en Terra Nova do Norte), donde ocasionaron la perdida de alimentos y objetos.

Observaciones realizadas durante los trabajos de campo de esta investigación permitieron confirmar que en general, estas ciudades presentan lo que Mustafa (2005) llamó de "paisajes amenazantes" debido a problemas como: insuficiencia (o ausencia) de sistemas de drenaje; pavimentación asfáltica incompleta o ausente; falta de limpieza de los arroyos y canales urbanos, incumplimiento de lo dispuesto sobre el ancho de las Áreas de Preservación Permanente (APP) de los arroyos urbanos; creciente impermeabilización del suelo; ocupación de áreas de riesgo; inadecuado transporte y/o disposición de los residuos sólidos, que afectan la limpieza urbana y dificultan el funcionamiento de los sistemas de drenaje (donde ellos existen) y erosión lineal de las calles no pavimentadas y carentes de sistema de drenaje pluvial. Paralelamente, eventos extremos de precipitación pueden inundar estaciones de tratamiento de agua localizadas en las proximidades de cuerpos hídricos, como ha ocurrido en Terra Nova do Norte. 
Situaciones similares son frecuentes en América Latina y el Caribe, cuyos países necesitan profundizar en el conocimiento de sus vulnerabilidades y exposición como condición para mejorar el gerenciamiento de riesgos de desastres (CDKN, 2012). Incluso en Europa, Vasseur (2018) identificó limitaciones de infraestructura que afectan la resiliencia necesaria para enfrentar potenciales impactos de eventos meteorológicos extremos en la isla de Gran Canaria (España). En Brasil, los estudios de Milanez y Fonseca (2011); Romero y Mendonça (2012); Cavalcanti y Aloufa (2014); Franca (2015) y Valverde (2017), también revelaron el papel del poder público en la construcción de vulnerabilidades (o de resiliencia).

Según Vaz (2010) las alteraciones climáticas pueden generar (o intensificar) problemas de salud oriundos de múltiples causas (inundaciones, consumo de agua no tratada, sistemas precarios de saneamiento básico y otras). Con base en esta realidad, fue cuestionada la incidencia de enfermedades vinculadas al agua y a vectores en las residencias. Los resultados indican una alta incidencia de gripe, diarrea y problemas respiratorios (enfermedades más frecuentes durante la estación lluviosa) (Gráfico 6)..

Gráfico 6 - Incidencia de enfermedades relacionadas con el agua y vectores en las viviendas muestreadas (en \% del total).

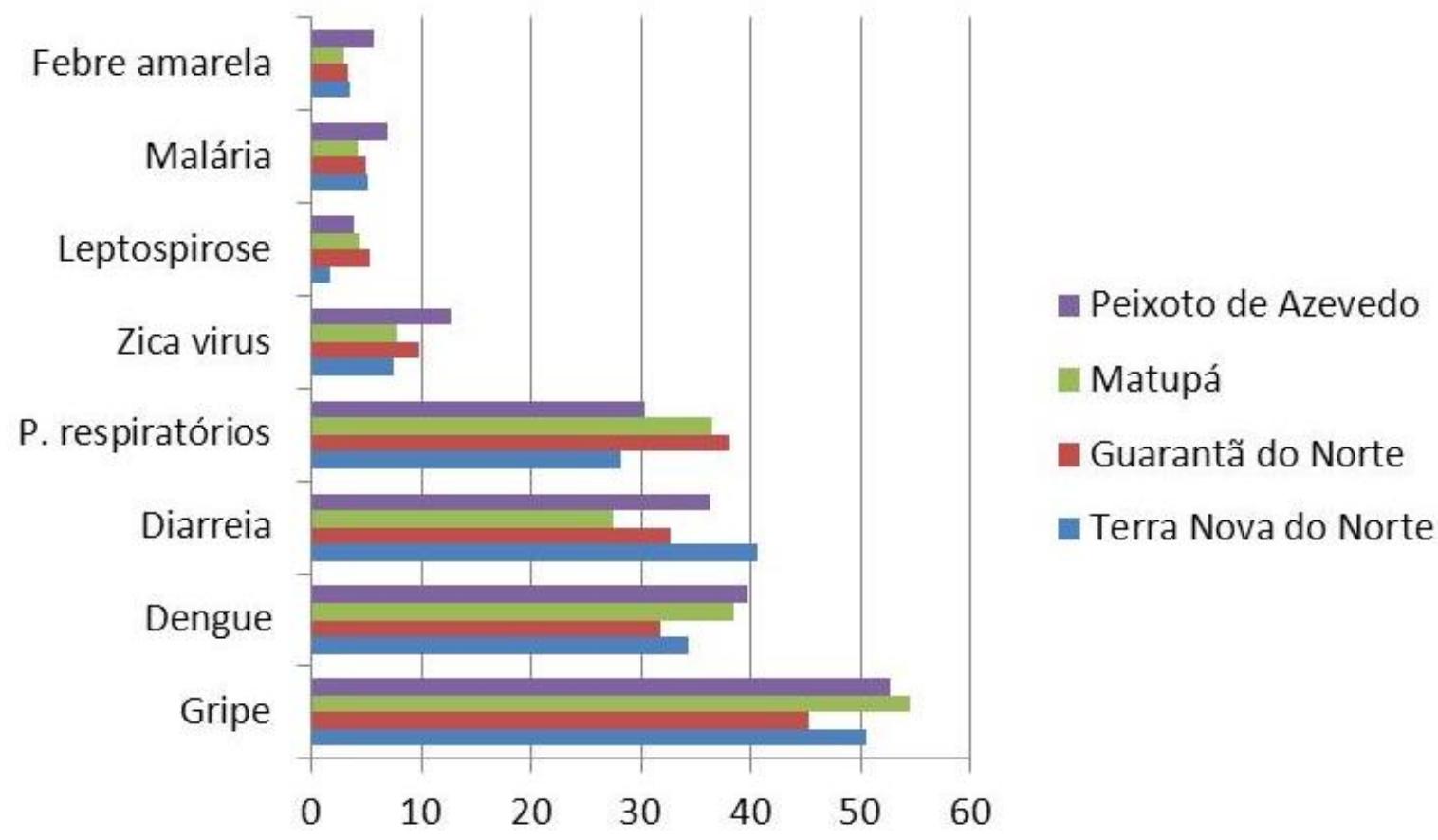

Fuente: Elaborado por los autores basado en el trabajo de campo (2019).

El hecho de que los niños sean un grupo con alta susceptibilidad para contraer enfermedades del sistema respiratorio (asma, sinositis, bronquitis, alergias y otras) asociado a causas como la emisión de gases durante los incendios rurales y la disminución de la humedad 
del aire durante la estación seca (VAZ, 2010), indica que estas podrían ser otras razones para explicar el elevado índice de problemas respiratorios mostrados en el Gráfico 6.

También es posible identificar la incidencia de enfermedades vinculadas a vectores como dengue, zica, malaria, leptospirosis y fiebre amarilla. La realidad constatada en las ciudades estudiadas indica que los tipos de enfermedades que afectan a la población constituyen impactos indirectos en la salud, como afirmaron Curriero et al. (2001, apud NOBRE e YOUNG, 2011). Tales impactos se pueden explicar por la influencia de factores como: proliferación de mosquitos durante la estación lluviosa, ingestión de (o contacto con) agua contaminada, y presencia de secaderos y almacenes de granos en ciudades como Guarantã do Norte y Matupá (refugios de vectores como murciélagos y ratones). Estudios realizados en Massaranduba/PB por Silva Filho; Morais; Silva (2013) y en Barcarena/PA por Marinho et al. (2016), también encontraron elevada incidencia de enfermedades cuya presencia es favorecida por factores socioeconómicos como habitación e higiene.

Cuando filtrados los resultados de las respuestas para identificar la ocurrencia de enfermedades en aquellas personas que llegaron a la región entre los años 1973 y 1996 (ellos representan 56,6\% del total de personas muestreadas) se confirmó que apenas la fiebre amarilla y la malaria (dos enfermedades causadas por vectores) fueron relatadas únicamente por personas que llegaron durante ese periodo. Se debe notar que las alteraciones climáticas deberán intensificar la incidencia de enfermedades como esas en la región, así como redistribuirlas para nuevos locales de propagación, lo que obliga a redoblar la atención a las vulnerabilidades de la población (PIGNATTI, 2004).

\section{Consideraciones finales}

La ocupación de la región norte de Mato Grosso fue acompañada de la creación de ciudades que se expandieron rapidamente sin una adecuada planificación de la infraestructura, lo que llevó a incrementar la vulnerabilidad de la población urbana. Los principales factores de vulnerabilidad (tanto extrínseca como intrínseca) identificados en las ciudades estudiadas en esta investigación son: bajo nivel de escolaridad; presencia de niños y ancianos en los domicilios; características constructivas de los inmuebles; uso de fosas como alternativa de drenaje sanitario; y abastecimiento de agua sin tratamento obtenida de pozos. Muchos de ellos contribuyen para la incidencia de enfermedades de origen hídrico, así como otras associadas a vectores. 


\section{Referencias}

ABNT-Associação Brasileira de Normas Técnicas. NBR 15220/2003: Desempenho térmico de edificações. Parte 2: Parte 2: Métodos de cálculo da transmitância térmica, da capacidade térmica, do atraso térmico e do fator solar de elementos e componentes de edificações. 2003. Disponível em:

http://www.labeee.ufsc.br/sites/default/files/projetos/normalizacao/Termica_parte2_SET2004. pdf Acesso em: 11 nov. 2018.

ABREU, N. J. A. de; ZANELLA, M. E. Percepção de riscos de inundações: estudo de caso no Bairro Guabiraba, Maranguape - Ceará. OKARA: Geografia em debate. Vol. 9, N .1 , p. 90107, João Pessoa: Universidade Federal da Paraíba, 2015. Disponível em: https://periodicos.ufpb.br/ojs2/index.php/okara/article/view/23859/13408 Acesso em: 13 nov. 2018.

ABREU, P. G. de.; ABREU, V. M. N.; COLDEBELLA, A.; LOPES, L. dos S.; CONCEIÇÃO, V. da.; TOMAZELLI, I. L. Análise termográfica da temperatura superficial de telhas. Revista Brasileira de Eng. Agrícola e Ambiental. vol.15, n.11, p. 1193-1198, Campina Grande, 2011. https://doi.org/10.1590/S1415-43662011001100013

ALMEIDA, L. C. M. de.; LORETO, M. D. S. de.; TEIXEIRA, K. M. D.; SILVEIRA, S. de F. R. Principais situações de vulnerabilidade social das famílias da Microrregião de Ubá, MG. Oikos: Revista Brasileira de Economia Doméstica, v. 27, n.1, p. 31-58, Viçosa-MG, 2016. Disponível em:

https://www.locus.ufv.br/bitstream/handle/123456789/20234/artigo.pdf?sequence=1\&isAllow ed=y Acesso em: 13 jun. 2018.

BODSTEIN, A.; LIMA, V. V. A. de.; BARROS, A. M. A. de. A vulnerabilidade do idoso em situações de desastres: necessidade de uma política de resiliência eficaz. Ambiente \& Sociedade. v. 17, n. 2, p. 157-174, São Paulo, 2014. https://doi.org/10.1590/S1414$\underline{753 X 2014000200011}$

BURSZTYN, M.; EIRÓ, F. Mudanças climáticas e distribuição social da percepção de risco no Brasil. Sociedade e Estado. Vol. 30, N . 2, p. 471-493, Departamento de Sociologia (Universidade de Brasília), 2015. https://doi.org/10.1590/S0102-699220150002000010

CAVALCANTE, J. da S. I.; ALOUFA, M. A. I. Percepção de riscos ambientais: uma análise sobre riscos de inundações em Natal-RN, Brasil. Investigaciones Geográficas. $\mathrm{N}^{0} .84$, p. 54 68, Boletín del Instituto de Geografía de la Uiversidad Nacional Autónoma de México, 2014. http://dx.doi.org/10.14350/rig.33709

CHANG, M. Estudo e mapeamento de vulnerabilidades a extremos climáticos no Estado do Paraná (Fase I). Relatório de pesquisa de Pós-doutorado apresentado ao Programa de Pós Graduação em Geografia da Universidade Federal do Rio de Janeiro-UFRJ. Rio de Janeiro, 2013, 116 p. Disponível em:

https://www.researchgate.net/publication/272274782_Estudo_e_Mapeamento_de_Vulnerabili dade_a_Extremos_Climaticos_no_Estado_do_Parana Acesso em: 10 mai. 2018.

CAF-Corporación Andina de Fomento. Indice de vulnerabilidad y adaptación al cambio climático en la región de América Latina y el Caribe, 2014, 212 p. Disponível em: https://scioteca.caf.com/handle/123456789/517 Acesso em: 13 out. 2018. 
CDKN-Rede de Conhecimento de Clima e Desenvolvimento (2012). Gerenciando extremos climáticos e desastres na América Latina e no Caribe: Lições do relatório SREX IPCC, 2012, 24 p. Disponível em: https://www.icict.fiocruz.br/sites/www.icict.fiocruz.br/files/Licoes _do_relatorio_SREX_IPCC.pdf Acesso em: 10 nov. 2018.

CEPED-Centro Universitário de Estudos e Pesquisas sobre Desastres. Atlas Brasileiro de Desastres Naturais: 1991 a 2012 / Volume Mato Grosso, 2. ed. rev. ampl. - Florianópolis: CEPED, UFSC, 2013, 109 p.

DUARTE, V. C. P. Desempenho térmico de edificações. 7a edição. Departamento de engenharia civil. Universidade Federal de Santa Catarina, Florianópolis, 2016, 239 p. Disponível em: http://www.labeee.ufsc.br/sites/default/files/disciplinas/Apostila ECV5161_v2016.pdf Acesso em: 15 ago. 2018.

FERREIRA, J. C. V.; SILVA, J. de M. Cidades de Mato Grosso: origem e significado de seus nomes. Cuiabá: Janina, 2008.

FIEGENBAUM, A. C. Análise comparativa de isolamento térmico entre painéis prémoldados, alvenaria de vedação de blocos de concreto e blocos cerâmicos para fins de conforto térmico. Monografia apresentada ao Curso de Engenharia Civil da Universidade do Vale do Taquari - UNIVATES, Lajeado, junho de 2018, 90 p. Disponível em:

https://univates.br/bdu/bitstream/10737/2245/1/2018AnaCristinaFiegenbaum.pdf Acesso em: 12 jul. 2019.

FRANCA, R. R. da. Eventos pluviais extremos na Amazônia meridional: riscos e impactos em Rondônia. Tese de doutorado apresentada ao Programa de Pós Graduação em Geografia da Universidade Federal do Paraná. Curitiba, 2015, 190 p. Disponível em:https://acervodigital.ufpr.br/bitstream/handle/1884/37677/R\%20-\%20T\%20\%20RAFAEL\%20RODRIGUES\%20DA\%20FRANCA.pdf Acesso em: 13 out. 2018.

FROTA, A. B.; SCHIFFER, S. R. Manual de Conforto Térmico: arquitetura, urbanismo. 5. Ed. São Paulo: Studio Nobel, 2001, 244 p. ISBN 85-85445-39-4. Disponível em: http://professor.pucgoias.edu.br/SiteDocente/admin/arquivosUpload/18350/material/ManualC onfortoTERMICO.pdf Acesso em: 11 out. 2018.

HARDOY J.; PANDIELLA, G. Urban poverty and vulnerability to climate change in Latin America. Environment and Urbanization, 21(1), p. 203-224, London-UK, 2009.https://doi.org/10.1177/0956247809103019

IPCC-Painel Intergovernamental sobre Mudanças Climáticas. Cambio climático 2014: Informe de síntesis. Contribución de los Grupos de trabajo I, II y III al Quinto Informe de Evaluación del Grupo Intergubernamental de Expertos sobre el Cambio Climático [PACHAURI, R. K.; MEYER, L. A. (Eds.)]. IPCC, Ginebra, Suiza, 157 p., 2014. Disponível em:https://www.ipcc.ch/site/assets/uploads/2018/02/SYR_AR5_FINAL full es.pdf Acesso em: 24 mai. 2018.

KAWABATA, C. Y. Desempenho térmico de diferentes tipos de telhado em bezerreiros individuais. Dissertação de mestrado apresentado ao Programa de Pós Graduação em Zootecnia da Universidade de São Paulo (Pirassununga), 2003, 108 p. Disponível em: http://www.usp.br/constrambi/producao_arquivos/depemp_termico_bezerros Acesso em: 27 jun. 2018.

LINDOSO, D.; EIRÓ, F.; ROCHA, J. D. Desenvolvimento Sustentável, Adaptação e Vulnerabilidade à Mudança Climática no Semiárido Nordestino: Um Estudo de Caso no 
Sertão do São Francisco. Documentos Técnico-Científicos. Rev. Econômica do Nordeste, vol. 44, Suplemento especial, p. 301-332, Fortaleza, 2013. Disponível em:

https://ren.emnuvens.com.br/ren/issue/view/20/showToc Acesso em: 25 jul. 2018.

MARANDOLA JÚNIOR, E; MODESTO, F. Percepção dos perigos ambientais urbanos e os efeitos de lugar na relação população-ambiente. Rev. bras. estud. popul. vol. 29, n. 1, p. 735, Rio de Janeiro, 2012. https://doi.org/10.1590/S0102-30982012000100002

MARTIS, R. D'A.; FERREIRA. L. C. Vulnerabilidade, adaptação e risco no contexto das mudanças climáticas. Revista Mercator. Vol. 11, N. 26, p. 275-276. Universidade Federal do Ceará, 2012. Universidade Federal do Ceará-CE. Disponível em:

http://www.mercator.ufc.br/mercator/issue/view/RM26 Acesso em: 23 jul. 2019.

MARINHO, J. S.; JESUS, I, M. de.; ASMUS, C. I. R. F.; LIMA, M. de O.; OLIVEIRA, D. C. Doenças infecciosas e parasitárias por veiculação hídrica e doenças respiratórias em área industrial, Norte do Brasil. Cadernos de Saúde Coletiva. Vol. 24, N ${ }^{0}$. 4, p. 443-451, Rio de Janeiro, 2016. https://doi.org/10.1590/1414-462x201600040120.

MATO GROSSO (Governo). Perfil - Regiões de Planejamento de Mato Grosso: 2017. $1^{\text {a }}$. Ed. Secretaria de Estado de Planejamento - Cuiabá, MT, 2017. 245 p. [ABUTAKKA, A.; SILVA, E. C. da.; GOMES, V. M. (Orgs.)]. ISBN 978-85-68279-02-1. Disponível em: http://www.seplan.mt.gov.br/-/4809749-perfil-das-regioes-deplanejamento?ciclo=cv_gestao_inf Acesso em: 26 jul. 2019.

MENEZES, L. C. P. de; OLIVEIRA, B. M. C. de; EL-DIER, S. G. Percepção ambiental sobre mudanças climáticas: estudo de caso no semiárido pernambucano. In: CONGRESSO BRASILEIRO DE GESTÃO AMBIENTAL, 2, 2011. Anais [....]. Londrina-PR: Universidade do Oeste do Paraná, 2011, p. I-036 (10 p.). Disponível em: www.ibeas.org.br/congresso/ Trabalhos2011/I-036.pdf Acesso em: 23 maio 2018.

MILANEZ, B.; FONSECA, I. F. da. Justiça climática e eventos climáticos extremos: uma análise da percepção social no Brasil. Revista Terceiro Incluído. Vol. 1, N ${ }^{0}$. 2, p. 82-99, Universidade Federal de Goiás: NUPEAT-IESA, 2011. Disponível em: https://www.revistas.ufg.br/teri/article/view/17842/10673 Acesso em: 21 maio 2018.

MORENO, G. A colonização no século XX. In: MORENO, G.; HIGA, T. C. S. (Orgs.). Geografia de Mato Grosso: território, sociedade, ambiente. Cuiabá: Entrelinhas, 2005.

MOURÃO, A. R. T.; CAVALCANTE, S. O processo de construção do lugar e da identidade dos moradores de uma cidade reinventada. Estudos de Psicologia. (Natal), vol.11, no.

2, Natal, p. 143-151, 2006.https://doi.org/10.1590/S1413-294X2006000200003

MUSTAFA, D. The production of an urban hazardsacape in Pakistan: modernity, vulnerability, and the range of choice. Annals of the Association of American Geographers, n. 95, Issue 3, p. 566-586, New Jersey-USA, 2005. Disponível em:

https://www.tandfonline.com/loi/raag20 Acesso em: 11 jun. 2019.

NOBRE, C. A.; YOUNG, A. F. (Eds.). Vulnerabilidades das megacidades brasileiras às mudanças climáticas: Região Metropolitana de São Paulo. Relatório Final. INPE/NEPO (Universidade Estadual de Campinas). 2011, 192 p. Disponível em:

https://www.nepo.unicamp.br/ publicacoes/livros/megacidades/megacidades_RMSP.pdf Acesso em: 17 nov. 2019. 
NOVACK, P. N. Formação da identidade espacial urbana no contexto da hipermodernidade: um estudo de caso em regiões administrativas de Pelotas, RS. Para Onde!?. Revista do Programa de Pós-graduação em Geografia. Universidade Federal de Rio Grande do Sul (UFRS). Porto Alegre: Vol. 9, N . 1, p. 30-40, 2015. Disponível em: https://seer.ufrgs.br/paraonde/article/view/83821

OLIVEIRA, S. de. Colonização e Massacre. 2. Ed. 2007, 106 p.

OLIVEIRA, G. S. de.; NOBRE, C. A. mudanças climáticas. In: Mudanças climáticas e mudanças socioambientais globais: reflexões sobre alternativas de futuro, p. 15-32 [TASSARA, E. T. de. O. (Coord.); RUTKOWSKI, E. W. (Org.)]. Brasília: UNESCO, IBECC, 2008, 184 p.

PANUTTI, R. História: Introdução, Fascículo 1. Cuiabá: Editora UFMT, 72 p. 2002.

PBMC, 2016: Mudanças Climáticas e Cidades. Relatório Especial do Painel Brasileiro de Mudanças Climáticas [RIBEIRO, S.K., SANTOS, A.S. (Eds.)]. PBMC, COPPE - UFRJ. Rio de Janeiro, Brasil. 98 p., 2016. ISBN: 978-85-285-0344-9. Disponível em:

http://www.pbmc.coppe.ufrj.br/documentos/Relatorio_UM_v10-2017-1.pdf Acesso em: 19 nov. 2018.

PIGNATTI, M. G. Saúde e Ambiente: as doenças emergentes no Brasil. Ambiente \& Sociedade. Vol. VII, nº. 1, p. 133-148, São Paulo, 2004. Disponível em: http://www.scielo.br/pdf/asoc/v7n1/23540.pdf Acesso em: 19 out. 2018.

PNA-Plano Nacional de Adaptação à Mudança do Clima. Vol. I - Estratégia Geral. Ministério do Meio Ambiente, Brasília, 2016, 59 p. Disponível em: http://www.pbmc.coppe.ufrj.br/documentos/PNA-Volume1.pdf Acesso em: 17 out. 2018.

ROGERS, W.; BALLANTYNE, A. Populações especiais: vulnerabilidade e proteção. RECIIS-Revista Eletrônica de Comunicação, Informação \& Inovação em Saúde. Vol. 2 (Suplemento), p. 31-41. Rio de Janeiro, 2008. http://dx.doi.org/10.3395/reciis.v2i0.865

ROMERO, H.; MENDONÇA, M. Ameaças naturais e avaliação subjetiva na construção da vulnerabilidade social diante de desastres naturais no Chile e Brasil. Revista Internacional Interdisciplinar INTERthesis. v. 9, n. 1, p. 127-180, Florianópolis, 2012. Disponível em: https://periodicos.ufsc.br/index.php/interthesis/issue/view/1892 Acesso em: 14 out. 2018.

SANTOS, F. de O.; PIMENTEL, M. R. dos S. Edificações e conforto térmico: a moradia como fonte de aprendizagem. Caminhos de Geografia. vol. 13, n. 44, p. 265-285, Uberlândia, 2012. Disponível em: http://www.seer.ufu.br/index.php/caminhosdegeografia/article/view/20876/11309

Acesso em: 12 set. 2018.

SEVEGNANI, K. B.; GHELFI FILHO, H.; SILVA, I. J. O. da. Comparação de vários materiais de cobertura através de índices de conforto térmico. Scientia Agrícola. vol. 51, n.1, p. 1-7, Piracicaba, 1994. https://doi.org/10.1590/S0103-90161994000100001

SILVA FILHO, A. C.; MORAIS, R. D. de.; SILVA, J. B. da. Doenças de veiculação hídrica: dados epidemiológicos, condições de abastecimento e armazenamento da água em Massaranduba/PB. GEOAMBIENTE ON-LINE. Revista Eletrônica do Curso de Graduação de Geografia. N ${ }^{0}$. 20, p. 83-96. Universidade Federal de Goiás-UFG (Campus Jataí), 2013. 
Disponível em: https://www.revistas.ufg.br/geoambiente/article/view/26089/15037 Acesso em: 5 ago. 2019.

SOUZA, L. C. D. de; CARVAlHO, M. A. C. de.; CORRÊA, B. da S.; SILVA, M. P. da. Consequências da atividade garimpeira nas margens do Rio Peixoto de Azevedo no perímetro urbano do município de Peixoto de Azevedo - MT. BIOTERRA-Revista de Biologia e Ciências da Terra. Vol. 8 - Número 2, p. 220-231, Universidade Federal de Sergipe - UFS, 2008. ISSN 1519-5228. Disponível em: http://joaootavio.com.br/bioterra/detalhe/volume8/22/ Acesso em: 25 set. 2018.

SOUZA, L. C. D. de.; CRUZ, A. B. da.; NASCIMENTO, R. B.; RIBEIRO, T. L.; SILVA, S. E. P. da. Caracterização dos moradores do município de Matupá. Caminhos de Geografia, vol. 8, n. 22, p. 88-104, Uberlândia, 2007. Disponível em: http://www.seer.ufu.br/index. php/caminhosdegeografia/issue/view/755 Acesso em: 28 mai. 2018.

SOUZA, T. F.; CASTRO, J. D. B. A percepção humana sobre meio ambiente e mudanças climáticas: Um estudo de valoração para os municípios: Silvânia, Abadiânia, Pirenópolis, Nerópolis e Goianápolis. In: IV CONGRESSO DE ENSINO, PESQUISA E EXTENSÃOCEPE, 4, 2017. Anais [...]. Universidade do Estado de Goiás (UEG)-Campus Pirenópolis, 2017 (s/p). Disponível em: https://www.anais.ueg.br/index.php/cepe/article/view/10407 Acesso em: 22 set. 2018.

TORRES, H. A demografia do risco ambiental. In: TORRES, H.; COSTA, E H. (Orgs.). População e Meio Ambiente: debates e desafios. São Paulo: Senac, p. 53-73, 2000.

VALVERDE, M. C. A interdependência entre vulnerabilidade climática e socioeconômica na região do ABC paulista. Ambiente \& Sociedade. v. XX, n. 3, p. 39-60. São Paulo, 2017. https://doi.org/10.1590/1809-4422asoc66r2v2032017

VASSEUR, E. N. Diagnóstico de riesgos y vulnerabilidades y adaptación al cambio climático en la isla de Gran Canaria. Resumen Ejecutivo. Consejo Insular de la Energía del Cabildo de Gran Canaria. 14 p., Septiembre 2018. Disponível em:

https://www.adaptecca.es/sites/default/files/editor_documentos/2018_grancanaria_diagnostic o_vulnerabilidad_riesgos.pdf Acesso em: 20 nov. 2019.

VAZ, D. dos S. Alterações climáticas, riscos ambientais e problemas de saúde: breves

Considerações. In: VI SEMINÁRIO LATINO AMERICANO DE GEOGRAFIA FÍSICA e II SEMINÁRIO IBERO AMERICANO DE GEOGRAFIA FÍSICA, 6, 2010. Coimbra. Anais [....]. Portugal: Universidade de Coimbra (s/p), 2010, 10 p. Disponível em: https://www.uc.pt/fluc/cegot/VISLAGF/actas/tema4/dirley Acesso em: 13 set. 2019.

VEYRET, Y. Os Riscos: o homem como agressor e vitima do meio ambiente. São Paulo: Contexto, 2007. 320 p.

WELZ, J.; KRELLENBERG, K. Vulnerabilidad frente al cambio climático en la Región Metropolitana de Santiago de Chile: posiciones teóricas versus evidencias empíricas. EURE. Vol. 42, n. 125, p. 251-272, Santiago (Chile), 2016. Disponível em: https://scielo.conicyt.cl/pdf/eure/v42n125/art11.pdf Acesso em: 15 set. 2019. 